Syntax Literate : Jurnal Ilmiah Indonesia p-ISSN: 2541-0849

e-ISSN : 2548-1398

Vol. 5, No. 7, Juli 2020

\title{
IMPLEMENTASI INFORMATION AND TECHNOLOGY (IT) DALAM PEMBELAJARAN PENDIDIKAN AGAMA ISLAM (PAI) PADA KELAS VII F SMPN 2 GUNUNG JATI KABUPATEN CIREBON
}

\author{
Oriza Aditya dan Verren Fitri Qomariyah \\ CV. Syntax Corporation Indonesia \\ Email: orizaaditia@gmail.com dan verrenfitriq@gmail.com
}

\begin{abstract}
This study aims to describe the data regarding: 1) to obtain data on Islamic Religious Education learning in class VII F of SMPN 2 Gunung Jati, 2) to analyze the implementation of IT media in the learning process of Islamic Religious Education in class VII F of SMPN 2 Gunung Jati, 3) to Describe the supporting and inhibiting factors of IT implementation in Islamic Religious Education learning in class VII F of SMPN 2 Gunung Jati. This research is a type of qualitative research by determining the informants using purposive sampling and snowball sampling. Data collection techniques using observation, interviews and documentation. Based on the results of research and discussion, it is known that IT which is applied in the learning process of Islamic religious education is very good and if this continues it will disrupt student learning. With the implementation of IT, it can add insight in the search for knowledge. Planning, with the MGMP forum fellow teachers can determine the IT media in the learning process. Implementation, the focus of IT itself is used one of them for Basic Education Data, Online Reporting of school data, School websites, projector devices used occasionally for certain teacher activities, UNBK. And evaluation in the form of a test that is an oral test and a written test to measure the results of the use of IT media by comparison not using IT media.
\end{abstract}

Keywords: Islamic Education; Information and Technology (IT); IT Learning

\section{Abstrak}

Penelitian ini bertujuan untuk mendeskripsikan data mengenai: 1) untuk memperoleh data tentang pembelajaran Pendidikan Agama Islam di kelas VII F SMPN 2 Gunung Jati, 2) untuk menganalisis tentang Implementasi media IT dalam proses pembelajaran Pendidikan Agama Islam pada kelas VII F SMPN 2 Gunung Jati, 3) untuk Mendeskripsikan tentang faktor pendukung dan penghambat implementasi IT pada pembelajaran Pendidikan Agama Islam di kelas VII F SMPN 2 Gunung Jati. Penelitian ini merupakan jenis penelitian kualitatif dengan menentukan informan menggunakan pengambilan sampel secara purposive sampling dan snowball sampling. Teknik pengumpulan data dengan menggunakan observasi, interview dan dokumentasi. Berdasarkam hasil penelitian dan pembahasan diketahui bahwa IT yang diapliksikan dalam proses pembelajaran pendidikan agama Islam ini sangatlah bagus dan jika hal ini berlangsung terus menerus hal ini akan menynjang belajar siswa. Dengan adanya implementasi IT ini 
dapat menambah wawasan dalam mencari ilmu pelajaran. Perencanaan, dengan adanya forum MGMP sesama guru dapat menentukan media IT dalam proses pembelajaran. Pelaksanaan, fokus IT sendiri digunakan salah satunya untuk Data Pokok Pendidikan, Pelaporan Online data sekolah, Website sekolah, alat proyektor dipakai sesekali untuk kegiatan tertentu guru, UNBK. Dan evaluasi berbentuk tes yakni tes lisan maupun tes tulis untuk mengukur hasil dari penggunaan media IT dengan komparasi tidak menggunakan media IT.

Keyword: Pendidikan Agama Islam; Information And Technology (IT); Pembelajaran IT

\section{Pendahuluan}

Indonesia juga secara luas dikenal sebagai sebuah Negara yang bercorak multibudaya (multikultural) yang terdiri dari ribuan suku bangsa yang tersebar diseluruh wilayahnya, memiliki ratusan dialek bahasa daerah, dan bermacam-macam keyakinan yang dianut, serta memiliki kompleksitas kebudayaan yang sangat banyak (Maksum, 2012).

Kondisi masyarakat yang plural baik dari segi budaya, ras, agama, dan status sosial ekonomi cenderung akan menimbulkan potensi benturan nuansa SARA termasuk nilai-nilai yang berlaku didalam masyarakat. Oleh karena itu diperlukan pendidikan multikultural dalam menanamkan nilai-nilai saling menghargai, sikap tenggang rasa, dan toleransi (Ambarudin, 2016).

Perbedaan kebudayaan yang disebutkan dikenal dengan istilah multikultural. Multikultural secara sederhana berarti kebudayaan yang beragam. Multikultural tidak hanya menyangkut masalah SARA (Suku, Agama, Ras, dan Antar golongan), melainkan keragaman yang lebih luas seperti kemampuan fisik maupun non-fisik, umur, status sosial, dan lain sebagainya. Kehidupan masyarakat yang multikultur perlu dipupuk agar muncul kesadaran pentingnya semangat multikuturalisme dalam kehidupan setiap individu dan masyarakat dalam melihat dan memaknai segala perbedaan yang ada. Multikulturalisme merupakan sebuah konsep atau ide yang menekankan adanya keanekaragaman kebudayaan dalam kesederajatan atau kesetaraan. Kesetaraan inilah yang menjadi titik tekan dari multikulturalisme (Maksum, 2012).

Pendidikan sebagai salah satu wadah pembinaan dan pengembangan diri generasi muda merupakan aspek yang perlu diperhatikan. Melalui dunia pendidikan segala potensi yang ada didalam diri seperti minat, bakat, dan kemampuan generasi muda dipupuk dan dikembangkan sebagai bekalnya sekarang dan masa yang akan datang, termasuk dalam memahami, menghadapi, meneriman, dan mengalami segala perbedaan (kemajemukan) yang ada disuatu masyarakat sehingga pendidikan yang berwawasan keanekaragaman atau pendidikan multikultural dapat menjadi sebuah paradigma yang dapat meminimalisir bahkan mengurangi ketegangan yang timbul karena tidak adanya rasa saling pengertian, toleransi, dan kesediaan dalam menerima sebuah perbedaan (Ramadhan, 2019)

Pendidikan merupakan hal yang sangat penting, dimana dunia diciptakan terkhususnya untuk manusia dalam pengembangan dan inovasi, agar dikelola dengan baik dan benar. Pada proses tersebut manusia sangat membutuhkan pendidikan agar 
menjadikan manusia yang manusia. Seperti dalam Q.S At-Talaq [65] ayat 12 ayat alquran dijelaskan:

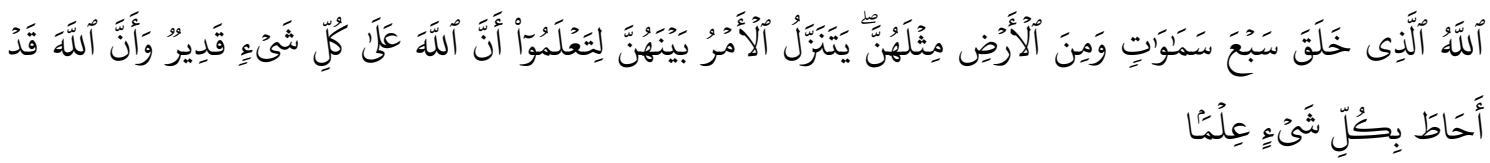

Artinya:

"Allah-lah yang menciptakan tujuh langit dan seperti itu pula bumi. perintah Allah Berlaku padanya, agar kamu mengetahui bahwasanya Allah Maha Kuasa atas segala sesuatu, dan Sesungguhnya Allah ilmu-Nya benar-benar meliputi segala sesuatu” (Kementrian Agama RI, 2014).

Pendidikan yang dijelaskan pada ayat diatas merupakan suatu tanda bahwa Allah SWT merupakan Dzat yang tidak ada yang bisa menandinginya, begitupun terhadap ilmu Allah SWT. Maka sebagai manusia kita hanya bisa berusaha dan bertaqwa sebagai hamba Allah SWT.

Dengan adanya ayat diatas Allah SWT juga memberikan tanda bahwa manusia dituntut untuk mempunyai ilmu dan terus belajar agar bisa menjadi manusia yang baik dan benar. Maka Allah SWT pada ayat diatas merupakan pendidik bagi manusia dan makhluk ciptaan-Nya.

Selain itu juga Allah SWT Berfirman dalam Q.S Al-Baqoroh Ayat 30-33:

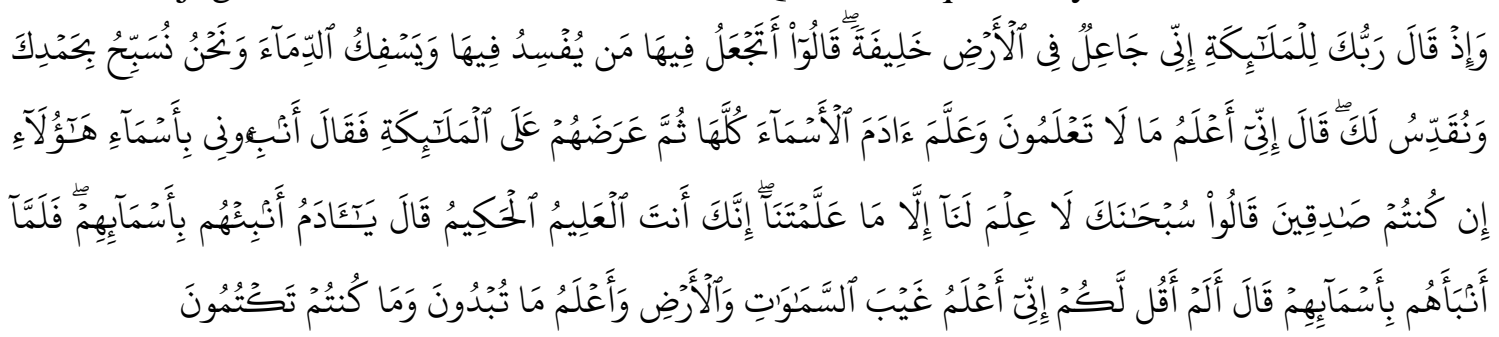

Artinya :

"30. ingatlah ketika Tuhanmu berfirman kepada Para Malaikat: "Sesungguhnya aku hendak menjadikan seorang khalifah di muka bumi." mereka berkata: "Mengapa Engkau hendak menjadikan (khalifah) di bumi itu orang yang akan membuat kerusakan padanya dan menumpahkan darah, Padahal Kami Senantiasa bertasbih dengan memuji Engkau dan mensucikan Engkau?" Tuhan berfirman: "Sesungguhnya aku mengetahui apa yang tidak kamu ketahui." 31. dan Dia mengajarkan kepada Adam Nama-nama (benda-benda) seluruhnya, kemudian mengemukakannya kepada Para Malaikat lalu berfirman: "Sebutkanlah kepada-Ku nama benda-benda itu jika kamu mamang benar orang-orang yang benar!" 32. mereka menjawab: "Maha suci Engkau, tidak ada yang Kami ketahui selain dari apa yang telah Engkau ajarkan kepada kami; Sesungguhnya Engkaulah yang Maha mengetahui lagi Maha Bijaksana. Allah berfirman: "Hai Adam, beritahukanlah kepada mereka Nama-nama benda ini." Maka setelah diberitahukannya kepada mereka Nama-nama benda itu, Allah berfirman: "Bukankah sudah Ku katakan 
kepadamu, bahwa Sesungguhnya aku mengetahui rahasia langit dan bumi dan mengetahui apa yang kamu lahirkan dan apa yang kamu sembunyikan?" (Kementrian Agama RI, 2014).

Berdasarkan pengertian diatas manusia menjadi maklhuk yang telah diiptakan allah SWT sebagai makkhluk yang sempurna dari makkhluk yang lainnya, maka konteks diatas manusia memiliki peran yang sangat penting karena manusia adalah sebagai khilafah atau leader di bumi ini. Quraish Shihab dalam (Kurniawan, 2018) menjelaskan bahwa khalifah dapat terjadi karena ada tiga unsur yang saling berhubungan, yaitu pertama adalah manusia sebagai khalifah. Khalifah adalah seorang hamba Allah yang mendapatkan mandat sebagai pelaksana, pengatur, penentu kebijakan dan menetapkan hukum-hukum sesuai dengan kehendak Allah dan aspirasi orangorang yang membaiatnya sebagai khalifah, kedua adalah bumi. Bumi atau wilayah tertentu adalah tempat atau sarana dalam melaksanakan kekhalifaan. Bumi merupakan tempat berbagai potensi yang dibutuhkan oleh manusia untuk mendapatkan kesejahteraan. Oleh karena itu, khalifah berkewajiban mengelola (isti'mara/ memakmurkan) bumi dan semua isinya atau sumber-sumbernya untuk kesejahteraan rakyat. Dengan demikian, seorang khalifah harus memiliki ilmu pengetahuan untuk mengelola objek kekuasaan itu, ketiga adalah hubungan antara pemilik kekuasaan dengan wilayah dan hubun gannya dengan pemberi kekuasaan (Allah) sebagai mustakhlilf. Namun hingga saat ini proses kearah leader dimuka bumi ini masih dalam progres, banyak pemimpin yang masih kurang amanah dalam tugasnya, ini juga merupakan proses belajar dan pembelajaran bagi yang lain dalam hal khalifah.

Menurut Undang-Undang Republik Indonesia Nomor 20 Tahun 2003 tentang sistem pendidikan nasional BAB 1 pasal 1 adalah Usaha sadar dan terencana untuk mewujudkan suasana belajar dan proses pembelajaran agar peserta didik secara aktif mengembangkan potensi dirinya untuk memiliki kekuatan spiritual keagamaan, pengendalian diri, kepribadian, kecerdasan, akhlak mulia, serta keterampilan yang diperlukan dirinya, masyarakat, bangsa dan negara Presiden Republik Indonesia dalam (Ngadiman \& Ratmawati, 2013).

Standar nasional pendidikan bertujuan menjamin mutu pendidikan Nasional dalam rangka mencerdaskan kehidupan bangsa dan membentuk watak serta peradaban bangsa yang bermartabat (Muhibudin, 2017).

Seperti yang telah dijelaskan pada Peraturan Pemerintah PP nomor 19 tahun 2005 dan PP nomor 32 tahun 2013 di dalam Standar Nasional Pendidikan bahwa seorang guru harus memiliki kompetensi pedagogik, kepribadian, profesional dan kompetensi sosial (Mulyasa, 2014).

Pendidikan pada zaman industri 4.0 dan zaman distrupsi seperti sekarang, pendidikan harus ikut menyesuaikan dengan zaman, dengan adanya teknologi dan informasi yang sangat berkembang pesat saat ini diharapkan mampu mengiringi proses aktifnya pembelajaran di sekolah.

Pada ayat 30 surat albaqarah malaikat menduga-duga atas manusia yang mana akan berbuat kerusakan dibumi, pertumpahan darah dan perselisihan. Dan juga sesuai 
pengalaman empiris malaikat yang sebelum manusia diciptakan tidak ada kerusakan seperti malaikat yang hanya menyucikan Allah SWT sebab itu malaikat bertanya-tanya persoalan manusia di jadikan khalifah dimuka bumi ini.

Berdasarkan tafsir jalalain juga disebutkan bahwa perbuatan kerusakan itu juga dilakukan oleh bangsa Jin yang dahulu diturukan ke bumi sebelum manusia, setelah mereka bangsa jin berbuat kerusakan allah mengirimkan malaikat ke bumi untuk membuang jin-jin ke gunung-gunung dan pulau-pulau terpencil (As-Suyuthi, 2010). Hal ini juga berdasarkan pengalaman bahwa dugaan itu timbul dari sebutan khalifah itu sendiri.

Sejarah kehidupan manusia dimuka bumi ini terus membuktikan bahwa apa yang dikhawatirkan malaikat itupun terjadi dan hingga saat ini hal tersebut terus menerus berlangsung dikehidupan. Seperti penebangan pohon, pengeboman yang terjadi di bali, Jakarta, dan lainnya yang telah terjadi diberbagai belahan dunia. Limbah yang mencemari laut dan biota lainnya, efek rumah kaca yang berdampak pa lapisan ozon sehingga menjadi tipis. Akan tetapi manusia diciptakan sebagai pemimpin dimuka bumi ini maka wallahu a'lam hanya allah yang mengetahui apa yang ada. Yang jelas manusia diciptakan sebagai pemimpin salah satu fungsinya juga yaitu untuk melerai perselihan dan pertumpahan darah dimuka bumi ini.

Maka pada proses manusia sebagai pemimpin ada pendidikan, pendidikan merupakan pembelajaran pengetahuan, keterampilan, dan kebiasaan sekelompok orang yang diturunkan dari satu generasi ke generasi berikutnya melalui pengajaran, pelatihan, atau penelitian. Pendidikan sering terjadi di bawah bimbingan orang lain, tetapi juga memungkinkan secara otodidak (Wikipedia, 2020).

Pengertian para ahli mengenai pendidikan: Bapak Pendidikan Nasional Indonesia ini menjelaskan bahwa pendidikan adalah tuntutan di dalam hidup tumbuhnya anak-anak, adapun maksudnya, pendidikan yaitu menuntun segala kekuatan kodrat yang ada pada anak-anak itu, agar mereka sebagai manusia dan sebagai anggota masyarakat dapatlah mencapai keselamatan dan kebahagiaan setinggi-tingginya. Pendidikan adalah usaha sadar untuk menyiapkan peserta didik melalui kegiatan bimbingan, pengajaran, dan atau latihan bagi peranannya di masa yang akan dating (Referensi, 2018). Pendidikan adalah sesuatu yang amat vital bagi kehidupan manusia sebagai upaya manusia untuk memanusiakan manusia, Nana Sudjana dalam (Salahuddin, 2012).

\section{Metode Penelitian}

Pada penelitian ini penulias menggunakan metode penelitian kualitatif karena posisi permasalahannya belum jelas, maka dibutuhkan penelitian mendalam dan bisa menjadi peran penting karena metofa menjadi penentu arah yang sesuai pada penelitian yang dilakukan. Penelitian metode kualitatif menunjukan pada fileld research (penelitian lapangan) dan juga buku referensi yang relevan.

Metode penelitian kualitatif merupakan metode yang berdasarkan pada nilai filsafat postpositivisme, yang digunakan dalam meneliti pada kondisi sebuah obyek alamiah, (lawannya adalah eksperimen) dimana peneliti adalah sebagai instrumen kunci, 
pengambilan sempel sumber data dilakukan secara purposive dan snowbaal, teknik pengumpulan dengan trianggulasi (gabungan), analisis data bersifat induktif/ kualitatif, dan hasil penelitian kualitatif lebih menekankan makna dari pada generalisasi (Sugiyono, 2017).

Penelitian kualitatif secara umum dapat digunakan untuk penelitian tentang kehidupan masyarakat, sejarah, tingkah laku, fungsionalisasi organisasi, aktivitas sosial, dan lain-lain. Salah satu alasan menggunakan pendekatan kualitatif adalah pengalaman para peneliti dimana metode ini dapat digunakan untuk menemukan dan memahami apa yang tersembunyi dibalik fenomena yang kadangkala merupakan sesuatu yang sulit untuk dipahami secara memuaskan (Rahmat, 2012). Lima ciri pokok sebagai karakteristik penelitian kualitatif yaitu (Rukajat, 2018):

1. Menggunakan lingkungan alamiah sebagai sumber data

2. Memiliki sifat deskriptif analitik

3. Tekanan pada proses bukan hasil

4. Bersifat induktif

5. Mengutamakan makna

Untuk penelitian ini menggunakan penelitian kualitatif maka akan menjelaskan tentang yang ada dilapangan sesuai dengan judul Implementasi Information and Technology (It) dalam Pembelajaran Pendidikan Agama Islam (PAI) Pada Kelas VII F SMPN 2 Gunung Jati Kabupaten Cirebon.

Lokasi dilaksanakannya penelitian ialah pada SMP Negeri 2 Gunung Jati yang beralamat di Jl. Raya Sunan Gunung Jati Ds. Grogol 45151 Telp. (0231) 8227453 Kabupaten Cirebon Provinsi Jawa Barat. peneliti memilih melakukan penelitian pada lokasi ini karena telah melakukan program pengalaman lapangan, juga SMP Negeri 2 Gunung Jati termasuk sekolah yang terbaik yang ada di kecamatan Gunung Jati, selain dengan prestasi akademik yang baik dengan ditunjang dengan prestasi non akademik yang dikatakan baik. Selain itu SMP Negeri 2 Gunung Jati telah melakukan manajemen mutu sekolah dengan dilakukannya akreditasi yang berhasil mendapatkan A (sangat Baik) dengan skor 93 yang diraih. Penelitian dilaksanakan pada April 2019 sampai dengan 17 Oktober 2019,

\section{Hasil dan Pembahasan}

\section{A. Hasil}

\section{Data hasil penelitian Implementasi IT dalam Pembelajaran Pendidikan Agama Islam pada kelas VII F di SMP Negeri 2 Gunung Jati}

Implementasi IT kelas VII F di SMP Negeri 2 Gunung Jati Setelah melakukan observasi dan wawancara terhadap narasumber yaitu Kepala Sekolah, Wakil kepala sekolah, Guru, Tenaga Staff IT, dan siswa. Peneliti mendapatkan data mengenai pembelajaran Pendidikan Agama Islam di kelas VII F SMPN 2 Gunung Jati. Sudah cukup baik dengan beberapa metode yang digunakan pada pembelajaran pendidikan agama islam sesuai program dan kurikulum. Walaupun berbeda - beda antusias dan 
inovasi setiap guru dan siswa dalam melaksanakan pembelajaran pendidikan agama islam.

Pengalaman dalam pembelajaran pendidikan agama islam pada saat mengajar, kurang menggunakan media IT, dikarenakan fasilitas dan motivasi guru menngunakan IT kurang antusias. Pada prosesnya guru menggunakan media pembelajaran dengan media lain contohnya memakai kertas, dengan metode yang pas. Menggunakan metode praktik seperti solat duha dimusola dan lainnya. Berikut macam-macam IT yang ditemukan di SMP Negeri 2 Gunung Jati:

a. Penggunaan IT melalui computer

Komputer menjadi salah satu media yang digunakan dalam pembelajaran teknologi agar dapat mempermudah proses pembelajaran. Di SMP Negeri 2 Gunung Jati terdapat 40unit komputer, untuk menunjang para siswa dalam belajar. Komputer ini pula juga digunakan pada saat Ujian Nasional secara online yang digunakan para siswa.

b. Penggunaan IT melalui Hp

Hp atau handpone saat ini sudah tidak asing, mengapa? Karena handpone sekarang ini sudah menjadi IT yang pokok dalam kehidupan seluruh orang, bukan hanya di bidang telekomunikasi tetapi hp ini juga berguna dalam proses pembelajaran siswa yang saat pandemi sekarang siswa diliburkan sekolah, salah satunya handpone ini bisa digunakan untuk sarana belajar menggunakan aplikasi google clasroom yang di donload di hp dan siswa dapat mengerjakan tugas ataupun belajar menggunakan aplikasi tersebut sehingga terhubungnya pembelajaran antara guru dan murid.

c. Penggunaan IT melalui Internet

Internet saat ini berkembang dengan sangat cepat, siswa dapat belajar melalui internet ketika di dalam buku pelajaran kurang pemahaman dalam belajar, dan siswa juga mendapat ilmu tambahan ketika siswa menggunakan internet. Di dalam internet terdapat blog orang ilmuan, yang mana menulis karya ataupun pengetahuan nya di internet, sehingga siswa juga dapat belajar secara aktif disekolah maupun diluar sekolah menggunakan internet sesuai apa yang diajarkan di sekolah.

\section{Implementasi media IT dalam pembelajaran Pendidikan Agama Islam pada kelas VII F SMPN 2 Gunung Jati}

a. Perencanaan Implementasi media IT dalam pembelajaran Pendidikan Agama Islam pada kelas VII F SMPN 2 Gunung Jati.

Perencanaan merupakan kegiatan yang dilakukan sebelum melaksanakan program, karena menjadi hal yang fundamental untuk menentukan hasil daripada tujuan itu sendiri, oleh karena itu perencanaan sangat penting.

Berdasarkan penelitian dilapangan bahwa perencanaan implementasi IT pendidikan agama Islam adalah sesuai dengan keterangan salah satu guru PAI: 
"Untuk peningkatan guru saya rasa semua guru itu meningkat, misalnya kita mengundang narasumber dari luar untuk membina guruguru smp setiap ajaran baru, misalnya ada MGMP kumpulnya di dinas latihan peningkatan mutu".

Selaku perwakilan guru MGMP dari SMPN 2 Gunung Jati sebelum melaksana program terlebih dahulu mengkoordinasikan dan meminta pendapat kepada forum MGMP setelah mendapatkan hasil baru mengkoordinasikan dengan kepala sekolah dan wakil kepala sekolah bagian kurikulum.

b. Pelaksanaan media IT dalam pembelajaran Pendidikan Agama Islam pada kelas VII F di SMP Negeri 2 Gunung Jati

Hasil dari penelitian melalui observasi dan wawancara kepada beberapa informan SMPN 2 Gunung Jati Kabupaten Cirebon (Kepala Sekolah, Wakil Kepala Sekolah, Guru PAI, Staff IT dan Siswa, peneliti memperoleh data tentang Implementasi IT pada SMPN 2 Gunung Jati Cirebon, Penggunaan media IT pada proses pembelajaran belum maksimal, indikator yang menjadi belum maksimal diantaranya, pada fokus IT di SMPN 2 Gunung Jati Cirebon sendiri IT digunakan salah satunya untuk Data Pokok Pendidikan, Pelaporan Online data sekolah, Website sekolah, alat proyektor dipakai sesekali untuk kegiatan tertentu guru, UNBK, Guru mengajar tidak selalu menggunakan media IT lebih sering menggunakan metode selain media IT.

Penggunaan Media IT menjadi tantangan kecil guru untuk selalu dituntut berinovasi dalam penyampaian materi pada proses pembelajaran di kelas. Akan tetapi semua guru tidak menolak media IT sebagai hal yang susah dan membawa angin segar pada proses pembelajaran di SMP Negeri 2 Gunung Jati.

c. Evaluasi implementasi media IT dalam pembelajaran Pendidikan Agama Islam di kelas VII F SMP Negeri 2 Gunung Jati

Evaluasi dilakukan melalui berbentuk tes yakni tes lisan maupun tes tulis untuk mengukur hasil dari penggunaan media IT dengan komparasi tidak menggunakan media IT.

"Ya dengan adanya itu guru merasa senang, dengan adanya ict anak merasa suka, dengan menggunakan tes lisan dan untuk evaluasi nya dengan adanya tayangan itu anak lebih mengena dan diterapkan dalam kehidupannya."

d. Faktor pendukung dan faktor penghambat Implementasi Media IT dalam Pembelajaran Pendidikan Agama Islam di kelas VII F SMP Negeri 2 Gunung Jati

Berdasarkan hasil temuan peneliti di lapangan bahwa implementasi media IT dalam pembelajaran Pendidikan Agama Islam di kelas VII F 
SMP Negeri 2 Gunung Jati berjalan dengan cukup baik, beberapa faktor pendukung dan penghambat diantaranya:

1) Faktor pendukung

a) Antusiasi siswa terhadap pembelajaran menggunakan media IT yang mengubah semangat dalam belajar

b) Adanya media laptop setiap guru yang sudah mempunyai.

c) Adanya proyektor dan LCD

d) Guru PAI SMP Negeri 2 Gunung Jati yang rajin mengajar

2) Faktor penghambat

a) Ketika pelaksanaan siswa tidak terkontrol bercanda

b) Fasilitas yang kurang memadai seperti listrik dikelas

c) Motivasi guru untuk menggunakan media IT

\section{B. Pembahasan}

Pembahasan sebelumnya didapatkan hasil dari penelitian observasi, wawancara dan dokumentasi tentang implementasi media IT dalam pembelajaran Pendidikan Agama Islam di kelas VII F SMP Negeri 2 Gunung Jati, pada bagian ini peneliti akan menguraikan bahasan yang sesuai dengan rumusan masalah dan tujuan penelitian di atas.

Implementasi pembelajaran PAI dengan sarana media IT akan berlangsung cukup baik ketika faktor pendukung tersebut bisa terpenuhi agar berlangsungnya pembelajaran PAI dengan baik. Media yang digunakan dalam implementasi IT antara lain:

e) Penggunaan IT melalui komputer

Dengan adanya media ini diharapkan siswa mampu menggunakan komputer sebagai sarana pembelajaran PAI ketika mnggunakan vidio interaktif dalam belajar.

f) Penggunaan IT melalui Hp

HandponE atau hp ini digunakan dalam belajar ketika siswa mendapatkan tugas secara online dari guru PAI, dengan ini diharapkan siswa mampu menggunakan hp dengan sebaik-baiknya dalam belajar.

g) Penggunaan IT melalui Internet

Internet diharapkan dapat menyelesaikan proses pembelajaran PAI ketika siswa mencari ilmu tambahan di internet dan ketika ada yang tidak dimengerti, siswa dapat menanyakan langsung kepada guru mata pelajaran PAI.

Implementasi Media IT dalam Pembelajaran Pendidikan Agama Islam di kelas VII F SMP Negeri 2 Gunung Jati dimulai dari program yang telah disusun oleh pihak guru serta tambahan dari setiap mata pelajaran PAI yang dipelajari menggunakan IT sebagai bahan tambahan yang dapat dicari di internet, agar para siswa dapat secara paham betul mengenai apa yang dipelajarinya.

Faktor-faktor yang mendukung Implementasi IT dalam Pembelajaran Pendidikan Agama Islam di kelas VII F SMP Negeri 2 Gunung Jati seperti: antusiasi siswa terhadap pembelajaran menggunakan media IT yang mengubah 
semangat dalam belajar, adanya media laptop setiap guru yang sudah mempunyai, adanya proyektor dan LCD, guru PAI SMP Negeri 2 Gunung Jati yang rajin mengajar.

Adapun faktor penghambat dari implementasi media IT dalam pembelajaran Pendidikan Agama Islam di kelas VII F SMP Negeri 2 Gunung Jati antara lain: ketika pelaksanaan siswa tidak terkontrol bercanda, fasilitas yang kurang memadai seperti listrik dikelas, motivasi guru untuk menggunakan media IT.

\section{Kesimpulan}

Perencanaan Implementasi media IT dalam pembelajaran Pendidikan Agama Islam pada kelas VII F SMPN 2 Gunung Jati melalui perwakilan guru MGMP sebelum melaksanakan program terlebih dahulu mengkoordinasikan dan meminta pendapat kepada forum MGMP setelah mendapatkan hasil baru mengkoordinasikan dengan kepala sekolah dan wakil kepala sekolah bagian kurikulum.

Pelaksanaan IT dalam pembelajaran Pendidikan Agama Islam pada kelas VII F di SMP Negeri 2 Gunung Jati dengan fokus IT sendiri digunakan salah satunya untuk Data Pokok Pendidikan, Pelaporan Online data sekolah, Website sekolah, alat proyektor dipakai sesekali untuk kegiatan tertentu guru, UNBK, Guru mengajar tidak selalu menggunakan media IT lebih sering menggunakan metode selain media IT.

Evaluasi implementasi media IT dalam pembelajaran Pendidikan Agama Islam di kelas VII F SMP Negeri 2 Gunung Jati berbentuk tes yakni tes lisan maupun tes tulis untuk mengukur hasil dari penggunaan media IT dengan komparasi tidak menggunakan media IT. 


\section{BIBLIOGRAFI}

Ambarudin, R. Ibnu. (2016). Pendidikan multikultural untuk membangun bangsa yang nasionalis religius. Jurnal Civics, 13(1), 28-45.

As-Suyuthi, Imam Jalaluddin Al Mahalli dan Imam Jalaluddin. (2010). Tafsir Jalalain. Bandung: Sinar Baru Algensindo.

Kementrian Agama RI. (2014). Al Qur'an dan Terjemahannya (1st ed.). Jakarta: PT. Hati Emas.

Kurniawan, Agung. (2018). Aktualisasi Nilai Khalifah Dalam Al-Quran. Jurnal AlDirayah, 1(1).

Maksum, Ali. (2012). Pluralisme dan Multikulturalisme. Yogyakarta: Aditya Media Publishing.

Muhibudin, Agus. (2017). Paradigma Pemanfaatan Teknologi Informasi (IT) Dalam Proses Pembelajaran PAI Untuk Meningkatkan Mutu Pendidikan (Study Di SMP Negeri 2 Ciledug Kabupaten Cirebon). Syntax Literate; Jurnal Ilmiah Indonesia, $2(2), 1-7$.

Mulyasa, E. (2014). Pengembangan dan Implementasi Kurikulum 2013. Kelima Bandung: PT Remaja Rosdakarya.

Ngadiman, A. Eliyana, \& Ratmawati, Dwi. (2013). Influence of transformational leadership and organization climate to the work satisfaction, organizational commitment and organizational citizenship behavior on the educational personnel of Sebelas Maret University, Surakarta. European Journal of Business and Management, 5(10), 97-114.

Rahmat, Pupu Saeful. (2012). Penelitian Kualitatif. Jurnal Equilibrium, 5(9), 2.

Ramadhan, Joan. (2019). Upaya Pengurus Pondok Pesantren Terhadap Penanaman Nilainilai Pendidikan Multikultural Dipondok Pesantren Hidayatul Mubtadiin Jati Agung Lampung Selatan. UIN Raden Intan Lampung.

Referensi, Zona. (2018). Pengertian Pendidikan | Definisi, Fungsi, Tujuan, dan JenisJenisnya. Retrieved from https://www.zonareferensi.com/pengertian-pendidikan/

Rukajat, Ajat. (2018). Pendekatan Penelitian Kualitatif (Qualitative Research Approach). Deepublish.

Salahuddin, Marwan. (2012). Pengembangan kurikulum madrasah diniyah takmiliyah. Cendekia: Jurnal Kependidikan Dan Kemasyarakatan, 10(1), 45-58.

Sugiyono. (2017). Metode Penelitian Pendidikan. Bandung: Alfabeta. 
Oriza Aditya dan Verren Fitri Qomariyah

Wikipedia. (2020). Pengertian Pendidikan. Retrieved from Wikipedia Ensiklopedia Bebas website: https://id.wikipedia.org/wiki/Pendidikan 